TAPROBANICA, ISSN 1800-427X. May, 2021. Vol. 10, No. 01: pp. 1-3.

(C) Research Center for Climate Change and Department of Biology, Faculty of Mathematics \& Natural Sciences, University of Indonesia, Depok 16424, INDONESIA.

http://www.taprobanica.org

https://doi.org/10.47605/tapro.v10i1.243

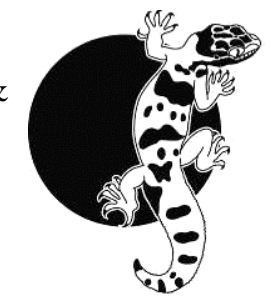

\title{
Covid-19, biodiversity conservation and welfare of wild animals partially under human control
}

It would feel wrong if I did not start this editorial with Covid-19 and its impact on biodiversity conservation in the broadest sense. There is no doubt that little will have had as much impact on biodiversity conservation throughout Asia as the Covid-19 pandemic. National and regional lockdowns, a shutdown of international travel, trade restrictions, temporary shutdowns of wet markets as well as live animal markets, closures of zoos and animal parks, closures of national parks to tourists, restriction of budgets for conservation agencies, etc. All these topics and how they affect various taxa in different regions as well as globally will be a fruitful area of research in years to come.

Here I will illustrate how Covid-19 will affect, in particular, the conservation and welfare of wild animals that are wholly or partially under human control. I will use examples from islands that inspired the name Taprobanica, presumed to be one of Sri Lanka, Sumatra or even another sizeable island somewhere in the Indian Ocean. Specifically, I will focus on Asian elephants, Elephas maximus and Sumatran orang-utans, Pongo abelii. Throughout Asia, as well as occurring in the wild in fragmented populations, these two species are kept in zoos, in wildlife attraction parks, as part of trekking experiences, and as reintroduced populations in natural settings, where they are visited annually by tens of thousands of people. While there are clear differences between countries, sites and institutions, in terms of funding a significant proportion comes from paying visitors. Covid-19, partial lockdowns and changing travel patterns mean a significant drop in tourists (Table 1), both domestic and international, and, hence, revenue.

Table 1. Effect of Covid-19 on quarterly visitor numbers (in million) for three countries in Asia; the first confirmed cases were reported on 13 January 2020 (Thailand), 27 January 2020 (Sri Lanka) and 2 March 2020 (Indonesia)

\begin{tabular}{|c|c|c|c|c|c|c|}
\hline & \multicolumn{2}{|c|}{ Thailand } & \multicolumn{2}{|c|}{ Sri Lanka } & \multicolumn{2}{|c|}{ Indonesia } \\
\hline & 2019 & 2020 & 2019 & 2020 & 2019 & 2020 \\
\hline Jan-Mar & 10.79 & 6.69 & 0.75 & 0.46 & 3.90 & 2.70 \\
\hline Apr-Jun & 8.976 & 0 & 0.20 & 0 & 4.15 & 0.44 \\
\hline Jul-Sep & 9.69 & 0 & 0.38 & 0 & 4.62 & 0.42 \\
\hline Oct-Dec & 10.35 & 0.01 & 0.52 & 0.01 & 4.10 & 0.51 \\
\hline
\end{tabular}

There are hundreds of Asian elephants that are under human care in Asia, with Myanmar and Thailand especially having large numbers of them in captive settings, but substantial numbers are also present in Sri Lanka and in Indonesia (Nijman 2014, Prakash et al. 2019, Flower et al. 2021). While often referred to as 'domestic' elephants, none of them are born in captivity but they fully depend on humans for their daily needs.

Bansiddhi et al. (2020) conducted an assessment of the welfare of captive Asian elephants in Thailand, where close to 4,000 of them are under human control. Based on research conducted preCovid-19, they concluded there are various ways to manage these elephants, and that while not all tourist activities are bad for welfare, it was essential they be managed in a way that meets physical, 
physiological and psychological needs. Overall, it is clear that improvements need to be made, and this is at least in part dependent on funding and a critical audience. With the significant decrease in the number of tourists visiting Thailand, and hence a significant decline in the number of people visiting captive elephants, this has become more challenging. In Sumatra in 2000 there were 362 elephants in six Elephant Training Centres (later renamed Elephant Conservation Centres) (Hutadjulu \& Janis 2002); in 2018 the International Elephant Foundation reported that more than 700 Sumatran elephants had been relocated to these centres, but that insufficient knowledge and funding had resulted in a serious lack of food and care for the elephants, resulting in many losses. Despite these losses, with at least 150 elephants in safari parks, tracking facilities and zoos in Sumatra, Java and Bali, it is safe to estimate the total number of Sumatran elephants in captive care in Indonesia numbers 700 individuals at least. Using figures from 2000, corrected for inflation, the cost of taking care of these elephants amounts to US\$ 185 per elephant per month. In the Elephant Conservation Centres, elephants are normally tethered by a metal chain and are released for foraging trips into the countryside or when taken for rides (with tourists) or exercise. Likewise, in many of the zoos, safari parks and elephant tracking facilities, the elephant's daily exercise regime (including walks and bathing in rivers) is tied closely to the presence of tourists. Reductions in tourist numbers thus not only results in a reduced income (and hence reduced funding for food and maintenance) but also to a reduction in activities.

One species of orangutan occurs on the island of Borneo (politically divided into Malaysia, Brunei and Indonesia) and two on the island of Sumatra (Indonesia). Banes et al. (2018) found that there were 466 orang-utans in 77 zoological institutions in Asia. Over the period 2007-2017, 994 orangutans were taken into rescue center facilities, bringing the total to 1,112 orangutans (Sherman et al. 2020). An additional 523 were translocated (i.e., taken from one area in the wild and after a period in captive care released into another area in the wild). While the majority of orangutans are found in the wild, and are not under human care, it is evident that the number of them that are fully or largely reliant on human care numbers in the low 1000s. The first rehabilitation centres for orangutans were opened in the 1970s and new ones continue to be set up. In the last twelve years four new facilities in Indonesia began accepting surrendered or confiscated orangutans, one each year in 2009, 2013, 2015 and 2017 (Sherman et al. 2020). Based on data from 2007 (Meijaard et al. 2012), and taking inflation into account, the cost of feeding and caring for orangutans in these centres can be estimated at $\sim$ US\$ 500 /month. Much of this funding comes from external (i.e., non-government) sources. Orangutan rehabilitation centres, just like other Great Ape rehabilitation centres, are also tourist sites, and although nearly every facility has explicit recommendation about the proper distance to protect against respiratory illness, tourists nevertheless often show up at the sites with symptoms that can harm the animals (Parreñas 2018). In practise many (former) release sites and the rehabilitation centres are open to, and reliant on, tourists. Russon \& Susilo (2014) gave a figure of US\$1,000 that tour operators donate after each visit to the organisations that sponsored or operated the tours, and tourists that visit rehabilitation centres often make financial donations following visits. Bukit Lawang (also known as Bohorok) in North Sumatra, is one of the most popular sites in Indonesia to see rehabilitated Sumatran orang-utans, Pongo abelii, and has been so for several decades. Typically, tourist experiences involved the viewing of the rehabilitant orangutans at feeding sites or during forest walks; the orangutans typically tolerate the tourists. Following the outbreak of Covid-19 in Indonesia and recognising that this could potentially be harmful to the orangutans - presumably the possibility that it might be transmissable to orangutans from human visitors (Gillespy \& Leendertz 2020), Bukit Lawang closed its gates in March 2020. It remained closed for several months, but it opened again in August 2020 and tourists (mainly from within Indonesia) returned to enter the area. Rather than a decline in confirmed cases of Covid-19 in Indonesia between March and August 2020, a significant increase was experienced (from 1,528 to 174,796). It is unclear to what degree tourists visiting Bukit Lawang may have the potential to cause harm to the orangutans, but it is evident that this needs to be monitored closely.

For the Asian elephants and the orangutans, despite numerous conservation initiatives and other mechanisms, international conventions, actions, interventions, and ministries responsible to protection and management, their natural habitat continues to deteriorate. Populations of all three orangutan species and Asian elephants are in decline and all are considered globally threatened. The threats are in part global (e.g., urbanisation, globalisation, climate change; disaffection and a general lack of 
political and societal support for conservation and animal welfare) but also local because more local constraints both impede and exacerbate conservation problems on the ground (e.g., poor governance; insufficient direct funding; insufficient resources, capacity, skills, and staffing at local and national governmental levels; lack of best management practices at virtually all levels; insufficient implementation and enforcement of existing legislation and guidelines). It is no exaggeration to view Covid-19 (and perhaps the reality of future pandemic zoonotic diseases) as one of the dominant threats to Asia's natural environment and Asia's economic, political and social systems. Given the increasing and evidently pervasive influence of Covid-19 on every aspect of government and society as well as our local and global environments, the pandemic (and the risk of future zoonotic diseases) is likely to be one of the most significant threats to species conservation in Asia (both in situ and ex situ). As such it rightly deserves to be given special consideration. Paradoxically Covid-19 can also serve as a catalyst for a critical paradigm shift to improve many aspects of society and socioeconomic development with regards to how we see the natural world. Covid-19 may become the new common thematic focus that ties future actions together, and it probably already has started influencing the implementation of decisive conservation and animal welfare measures in Asia and beyond.

\section{Literature cited}

Banes, G.L., W. Chua, M. Elder, and J. Kao (2018). Orang-utans Pongo spp in Asian zoos: current status, challenges and progress towards long-term population sustainability. International Zoo Yearbook, 52 (1): 150-163.

Bansiddhi, P., J.L. Brown, and C. Thitaram (2020). Welfare assessment and activities of captive elephants in Thailand. Animals, 10 (6): 919.

Flower, E.K., G.L. Burns, and D.N. Jones (2021). How tourist preference and satisfaction can contribute to improved welfare standards at elephant tourism venues in Thailand. Animals, 11 (4): 1094.

Gillespie, T.R. and F.H. Leendertz (2020). COVID-19: protect great apes during human pandemics. Nature, 579 (7800): 497.

Hutadjulu, B. and R. Janis (2002). The care and management of domesticated elephants in Sumatra, Indonesia. In: Baker, I. and M. Kashio (eds.). Giants on Our Hands: Proceedings of the International Workshop on the Domesticated Asian Elephant. Dharmasarn Co. Ltd, Bangkok: 59-65.

Parreñas, J.S. (2018). Decolonizing Extinction: The Work of Care in Orangutan Rehabilitation. Duke University Press, Durham: 288pp.

Meijaard, E., S. Wich, M. Ancrenaz, and A.J. Marshall (2012). Not by science alone: why orangutan conservationists must think outside the box. Annals of the New York Academy of Sciences, 1249 (1): $29-44$.

Nijman, V. (2014). An assessment of the live elephant trade in Thailand. Traffic International, Cambridge: 38pp.

Prakash, S.L., P. Perera, D. Newsome, T. Kusuminda, O. and Walker (2019). Reasons for visitor dissatisfaction with wildlife tourism experiences at highly visited national parks in Sri Lanka. Journal of Outdoor Recreation and Tourism, 25: 102-112.

Russon, A.E. and A. Susilo (2014). Orangutan tourism and conservation: 35 years' experience. In: Russon A.E. and J. Wallis (eds.). Primate Tourism: A Tool for Conservation? Cambridge University Press: 76-97.

Sherman, J., M. Ancrenaz, and E. Meijaard (2020). Shifting apes: Conservation and welfare outcomes of Bornean orangutan rescue and release in Kalimantan, Indonesia. Journal for Nature Conservation, 55: 125807.

Vincent Nijman

Professor in Anthropology

Oxford Brookes University

School of Social Sciences

Oxford, UK

Section Editor: Taprobanica, the journal of Asian Biodiversity

May $10^{\text {th }}, 2021$ 